\title{
El Caribe como objeto de estudio histórico: una aproximación desde las publicaciones en el Anuario de Estudios Americanos/
}

\author{
The Caribbean as a Field of Historical Studies: an Approach \\ from the Publications in the Anuario de Estudios Americanos
}

\author{
Sigfrido Vázquez Cienfuegos \\ ORCID iD: https://orcid.org/0000-0002-9030-3915 \\ Universidad de Extremadura
}

En este artículo se analiza la producción historiográfica referida al Caribe que ha sido publicada en el Anuario de Estudios Americanos en sus 75 años de vigencia ininterrumpida. Entre 1944 y 2018 hemos contabilizado un total de 180 trabajos publicados. Aplicando una metodología cuantitativa en conjunción con una revisión analítica hemos logrado unos resultados que consideramos útiles desde el punto de vista de la investigación historiográfica, constatando que el Anuario de Estudios Americanos es una publicación de referencia para estudiar los diferentes espacios caribeños desde la llegada de los europeos hasta el siglo XX.

Palabras clave: Caribe; Historiografía; Revista americanista.

This article analyzes the historiographical production referred to the Caribbean that has been published in the Anuario de Estudios Americanos in the 75 years of uninterrupted validity. I have counted 180 works published between 1944 and 2018. I have achieved some results that we consider useful from the point of view of historiographical research applying a quantitative methodology and an analytical review. We have verified that the Anuario de Estudios Americanos is a reference publication to study the different Caribbean spaces since the arrival of Europeans until the 20th century.

KEYwords: Caribbean; Historiography; Latin America review.

Copyright: (C) 2018 CSIC. Este es un artículo de acceso abierto distribuido bajo los términos de la licencia de uso y distribución Creative Commons Reconocimiento 4.0 Internacional (CC BY 4.0). 


\section{Introducción: algunas cuestiones metodológicas ${ }^{1}$}

Como señalaba Juan B. Amores en un trabajo similar a este publicado hace casi tres décadas, todo intento de análisis de una producción historiográfica está lleno de riesgos. ${ }^{2}$ Esto ocurre en mayor medida cuando este estudio se realiza sobre una única publicación, Anuario de Estudios Americanos, donde los resultados por fuerza no pueden ser más que parciales. Por ello hemos considerado que lo más adecuado era sustentar nuestro trabajo sobre una metodología fundamentalmente cuantitativa, pretendiendo mantener sobre cuestiones numéricas y estadísticas la pretensión de objetividad que debe dirigir todo análisis científico, así como lograr unos resultados que fueran útiles para otros investigadores.

Y es que realizar una investigación sobre las publicaciones de artículos sobre el Caribe aparecidos en el Anuario de Estudios Americanos no ha sido algo sencillo. El volumen de trabajos que hemos contabilizado ha llegado nada menos que a los 180 artículos publicados entre 1944 y 2018. Sin embargo, no es ese el total de artículos referidos al Caribe pues hemos discriminado todos aquellos que no fueran específicamente de historia, descartando por ejemplo los dedicados a literatura, historia del arte o antropología.

Otras de las cuestiones ha sido dirimir el espacio concreto de estudio. La definición del área Caribe nunca ha sido fácil desde el punto de vista geo-histórico, y menos para un análisis de carácter historiográfico como el que se pretende hacer aquí. Para algunos geógrafos e historiadores hay que incluir en ella además de a las Antillas, a las Floridas, el Caribe novohispano (incluido Yucatán), el centroamericano y las «fachadas caribeñas» de Venezuela y Colombia. ${ }^{3}$ Efectivamente, las relaciones de todo tipo entre aquellos distintos espacios fueron intensas en la época moderna o colonial, que es a la que atiende principalmente la mayoría de los trabajos publicados en el Anuario. Sin embargo, hemos decidido excluir de nuestro estudio los trabajos referidos al Caribe novohispano y centroamericano por una razón práctica —elevaría en exceso el número de trabajos a analizar en este breve estudio - y otra historiográfica: estas dos regiones han sido tratadas

1 Este texto es resultado en parte del apoyo del proyecto de investigación del Centro de Estudios Iberoamericanos de la Metropolitan University of Prague, financiado por el Ministerio de Educación y Deportes de la Republica Checa, código 57-02, en el año 2018.

2 Amores, 1990.

3 Grafenstein, 1997, 30-31. 
tradicionalmente por la historiografía de la América colonial como vinculadas al virreinato novohispano o a la Audiencia de Guatemala, o como área autónoma (caso de Yucatán) más que al Caribe.

También se han excluido los trabajos dedicados a los protagonistas del Descubrimiento y primer dominio en América, pues aunque tuvieron su desarrollo en el Caribe solo los hemos cuantificado en aquellos casos que se refieren a acciones específicas en el área. ${ }^{4}$

Una vez establecidos los parámetros generales y contabilizado el número de trabajos que cumplían con estos criterios, hemos realizado una base de datos en la que se han referido los siguientes campos: nombre y apellidos del autor (iguales datos para coautores), nacionalidad de los mismos, título del artículo, volumen, fecha de publicación, páginas, idioma del texto, espacio geográfico concreto, época objeto de estudio, temática principal y otras temáticas secundarias. Con estos datos consideramos que era factible realizar un análisis cuantitativo válido $\mathrm{y}$, como podrá comprobarse, se han podido extraer algunas conclusiones al respecto, que esperamos puedan servir para que en el futuro se realicen otros estudios complementarios.

Otra de las limitaciones es la reducida producción de trabajos dedicados al análisis historiográfico sobre todo el conjunto del Caribe, si exceptuamos el volumen VI de General History of the Caribbean dedicado a metodología e historiografía, editado por la UNESCO en $1999 .{ }^{5}$ Hemos contado con análisis parciales dedicados fundamentalmente a la isla de Cuba. La única monografía, que realmente es una compilación de textos antologados por Carmen Almodóvar sobre la historiografía cubanista española de finales del siglo XX, cuenta con aparato introductorio muy útil. ${ }^{6}$ En cuanto a artículos, reseñar el publicado por Juan B. Amores en 1990 sobre la historiografía española sobre Cuba colonial entre 1940 y 1989, ya citado, o el de Antonio Santamaría y Consuelo Naranjo sobre la historia social en Cuba entre 1868 y 1914. ${ }^{7}$ También hemos tenido que buscar referencias

4 Hemos consultado varios trabajos sobre protagonistas del descubrimiento y primera colonización que solo trataban de manera muy tangencial el área Caribe.

5 Higman, 1999. En esta monografía encontramos trabajos de Fe Iglesias, «Historiography of Cuba», 343-386; Roberto Cassá, «Historiography of the Dominican Republic», 388-418; Fernando Picó, «Historiography of Puerto Rico», 417-450; o Anne Pérotin-Dumon y Serge Mam-Lam-Fouck, «Historiography of the French Antilles and French Guyana», 631-664; entre otros espacios de los que, como veremos, han tenido presencia en el Anuario de Estudios Americanos. Si bien consideramos que es un trabajo de gran utilidad, sería necesaria una actualización al haber pasado casi veinte años desde su edición.

6 Almodóvar, 2007, 11-98.

7 Santamaría y Naranjo, 1999. 
en trabajos generales como ha sido el estudio sobre el americanismo en Sevilla de Calderón Quijano. ${ }^{8}$

Otra cuestión preliminar antes de pasar al desarrollo propio del trabajo de análisis es señalar el funcionamiento de la revista, que afectó a la incorporación de trabajos en general, pero específicamente tuvo incidencia en la publicación de artículos sobre el Caribe. Durante los primeros años la revista no contó con un organigrama de dirección y consejo de redacción, sino que estuvo a cargo de la propia dirección de la Escuela de Estudios Hispano-Americanos. Hasta la década de 1960 la revista funcionó básicamente como una herramienta para difundir los avances del americanismo sevillano, aunque también contó con trabajos de autores no españoles vinculados temporalmente a la EEHA y que en la mayoría de los casos habían realizado sus investigaciones en el Archivo General de Indias. Valga como explicación la evolución histórica de la conformación de la dirección de Anuario. Los cuatro primeros volúmenes no especifican la ordenación del consejo de redacción, ni nombre de director alguno. Será a partir del volumen V, de 1948, cuando aparezca por primera vez un consejo de redacción. Este esquema se mantiene de forma similar en los siguientes números, aunque desde 1950 no consta redactor jefe. Sin embargo, curiosamente en el año 1956 (volumen XVI) no se incluye el consejo de redacción, sino únicamente a Antonio Muro Orejón como redactor jefe y a Francisco Morales Padrón como secretario de redacción. Sería con la llegada de este último a la dirección de la revista en 1966, cuando Anuario iniciaría su auténtico recorrido como revista de carácter internacional, aunque esto tuvo que ver directamente también con la expansión de los estudios americanistas en otros países en aquel momento.

Esta evolución quedó plasmada tanto en el origen de los autores como en la metodología de los artículos publicados, como comprobaremos en los trabajos relativos al Caribe, aunque consideramos que esto puede ser extrapolable a todo el conjunto de la publicación. De los datos extraídos podría considerarse que los distintos directores, apoyados en sus consejos de dirección, han imprimido su sello y en el caso de aquellos especializados en el Caribe o en temas con fuerte presencia en las Antillas, como es la esclavitud. Esto podría inferirse del número de artículos e incluso en la publicación de monográficos, como veremos durante distintas direcciones. Sin embargo, somos conscientes de que una parte importante de la razón

8 Calderón, 1987, XCI. 
de la publicación de artículos referidos al Caribe ha estado relacionada con la actualidad de las temáticas y la consecuente disponibilidad de trabajos presentados para su publicación.

Finalmente, un aspecto inicial a destacar con respecto a los artículos dedicados al Caribe en Anuario de Estudios Americanos es que están escritos en uno de estos dos idiomas: español o francés. El mayoritariamente usado es el español, pues solo seis artículos están publicados en francés, lo que supone el $4 \%$ de los trabajos. Sería necesario señalar que esta circunstancia se debe a que durante décadas la lengua internacional por excelencia para los temas americanistas ha sido el español. ${ }^{9}$

\section{Presencia del Caribe en el conjunto de la revista}

El primer dato reseñable es que los 180 artículos con temática antillana suponen casi el $15 \%$ de los 1228 publicados por Anuario de Estudios Americanos [AEA] entre 1944 y junio de 2018. ${ }^{10}$ De los 75 volúmenes aparecidos hasta el momento, en 61 se ha presentado algún artículo sobre el Caribe, es decir, en más del $81 \%$ de las publicaciones anuales ha tenido presencia esta área. Si nos fijamos solo en los primeros 50 volúmenes que fueron anuales, en 44 de ellos apareció un artículo sobre el Caribe. En cuanto a la cantidad total de números publicados (98), en 71 de ellos ha aparecido algún trabajo sobre el Caribe (hay que recordar que desde 1993 se publican dos números por volumen). Estos datos por sí mismos mostrarían la importancia que ha tenido para la revista el espacio a estudio. Sin embargo, desde 2011 (volumen LXVIII-1) solo han sido publicados dos artículos más, uno en 2014 y otro en $2018 .{ }^{11}$ Este descenso apunta una significativa tendencia al constituir el periodo con menor densidad de trabajos

9 Valga como ejemplo el americanismo checoslovaco, en el que estoy especializado: al fundar su publicación de referencia en 1967, la revista Ibero-Americana Pragensia utilizó como lengua principal el español con la intención de participar en los debates internacionales sobre historia de América. Lo mismo ocurrió con la revista Latinskaia Amerika publicada en Moscú, solo por señalar unos ejemplos «exóticos». Hasta hoy día siguen manteniendo esta política. De un tiempo a esta parte las autoridades académicas españolas parecen obcecadas en considerar como un marchamo de internacionalidad el escribir en inglés, negando incomprensiblemente esta consideración a las producciones en español sobre historia de América. Esta tendencia no ha afectado a las publicaciones sobre el Caribe en la revista.

10 Los artículos contabilizados han sido aquellos referidos a trabajos originales, incluyendo los dedicados a historiografía y bibliografía, y excluyendo presentaciones de monográficos o dosieres, crónicas o reseñas.

11 Vázquez y Amores, 2011. Santamaría García, 2014. Espino López, 2018. 
publicados de toda la serie sobre el Caribe en la revista. No hemos sabido desentrañar las razones de esta situación, aunque es posible que se deba a una apertura del Anuario a otros aspectos de la historiografía americanista.

El Anuario ha dedicado a lo largo de su historia nada menos que tres volúmenes monográficos a temáticas estrictamente caribeñas. En el volumen XLIII, de 1986, aunque nominalmente dedicado a la esclavitud en general al cumplirse los cien años de la abolición definitiva de la misma, 24 de los 26 artículos publicados fueron sobre territorios en el área de interés en este estudio. Esta relación es lógica teniendo en cuenta que para el momento de la abolición era en el Caribe hispano donde se mantenía esta institución de manera destacada. Este volumen fue iniciativa de su directora Enriqueta Vila Vilar, reconocida especialista en la temática.

El monográfico más significativo con respecto a la importancia del Caribe para la revista aquí estudiada quizás sea el volumen LI-2, de 1994. En conmemoración de los 50 años de la salida de la revista se publicó un número específico sobre los estudios del Caribe «por ser este un campo de especialización al que la Escuela de Estudios Hispano-Americanos del CSIC, la cuna de la revista, ha dedicado gran parte de sus investigaciones en estos años». ${ }^{12} \mathrm{El}$ volumen reúne quince artículos aunque hemos contabilizado trece, atendiendo a los criterios metodológicos expuestos, dado que dos de los artículos son sobre Venezuela en general y no específicamente de la costa caribeña.

El tercer número monográfico con temática fundamentalmente antillana fue el LV-1, de 1998, que conmemoró el centenario de 1898 con el título «En torno al "98"». En este caso catorce de los quince artículos estuvieron dedicados a Cuba o Puerto Rico y tan solo uno a Filipinas. Este ha sido uno de los temas que más interés ha despertado en la historiografía hispana de las últimas décadas. ${ }^{13}$ Según estimaciones hechas por Consuelo Naranjo y Antonio Santamaría, la conmemoración de 1898 había generado hasta el año 2002 nada menos que «más de 100 libros y 800 artículos que estudian la transición del siglo XIX al XX en América Latina». ${ }^{14}$ Por tanto, Anuario de Estudios Americanos con su monográfico se sumó de manera destacada a este esfuerzo investigador. Este también fue el caso de la otra publicación americanista editada por el CSIC, Revista de Indias, que sacó a la luz el

12 Consejo de Redacción, 1994, 13.

13 Véase Almodóvar, 2007, 43-65.

14 Santamaría y Naranjo, 1999. 
monográfico «Cuba 1998», coordinado por Consuelo Naranjo y Alejandro García. $^{15}$

Tanto el volumen LI-2 como el LV-1 se debieron muy posiblemente a iniciativas de su consejo de redacción así como a la dirección de Rosario Sevilla Soler, especialista en temas sobre el Caribe.

\section{Autores participantes}

Un total de 155 autores diferentes han publicado sobre el Caribe en Anuario de Estudios Americanos, de los cuales catorce aparecen como coautores de las investigaciones. Esto nos indica que esta publicación cuenta con una más que significativa muestra de los investigadores que han dedicado sus esfuerzos al área de estudio aquí observada. Consideramos que la presencia de historiadores estuvo relacionada, especialmente hasta la organización formal del consejo editorial en la década de 1960, con los contactos personales de los directores de la propia revista y con los vínculos de los investigadores de la Escuela de Estudios Hispano-Americanos. ${ }^{16}$

Del cómputo total, 133 autores cuentan con un solo artículo, mientras que 22 han publicado más de una vez. Estos últimos han escrito 58 trabajos, es decir, aproximadamente un tercio de todo lo publicado. El más destacado numéricamente hablando es el francés Gabriel Debien, con nueve artículos como único autor, más uno como coautor. Hay que señalar que de estos, cinco son informes acerca de la bibliografía sobre las Antillas de lengua francesa; esta serie de artículos fue iniciativa de Francisco Morales Padrón y fueron publicados entre 1954 y $1973 .{ }^{17}$ Debien fue uno de los más importantes especialistas en los aspectos africanos y esclavistas de las Antillas francesas de los siglos XVII y XVIII, especialmente en Saint Domingue. Su obra está basada en el rigor de la investigación y el análisis de fuentes, siendo una parte fundamental de su producción las crónicas bibliográficas, ediciones de textos y monografías. Llevado de un respeto extremo a las fuentes primarias retrasó la publicación de su primera monografía hasta 1974: Les esclaves aux Antilles françaises (XVII ${ }^{e}$-XVIII ${ }^{e}$ siècles) ${ }^{18}$ Sus publicaciones en Anuario de Estudios Americanos son una excepcional representación de

15 Naranjo y García, 1998.

16 Para un rápido acercamiento a la historia de la propia revista véase Bernabéu y Varela, 2010.

17 Calderón, 1987, XCI.

18 Debien, 1974. Bouche, 1990. 
su obra, así como una fuente indispensable para conocer la bibliografía e historiografía de las Antillas francesas durante el siglo XX.

Ninguno de los demás autores tiene más de cuatro artículos publicados y todos ellos son historiadores españoles: Francisco Morales Padrón, Luis Navarro García y Francisco Castillo Meléndez. Con tres trabajos encontramos a los también españoles Manuel Luengo Muñoz, María del Carmen Borrego Plá, Pablo Tornero Tinajero y Consuelo Naranjo Orovio, quien tiene dos como única autora y uno más en coautoría. Entre los autores con, al menos, dos trabajos publicados encontramos a los franceses Anne Pérotin-Dumon, Paul Estrade, Louis-André Vigneras y Jean Pierre Tardieu; a los españoles J. Raúl Navarro García, Pablo Tornero, Bibiano Torres, Rosario Sevilla, José Llavador Mira, Fernando de Armas Medina y Juan B. Amores Carredano (este con uno como único autor y otro en coautoría); el portorriqueño István Szászdi, la cubana María del Carmen Barcia Zequeira y los dominicanos Roberto Cassá y Genaro Rodríguez Morel (que tienen un trabajo en coautoría, con Cassá como principal).

Con respecto al elenco de historiadores que han contribuido al conocimiento de la historia del Caribe con sus participaciones en el Anuario hay que señalar la fuerte presencia de españoles, muchos de ellos los representantes de la llamada «escuela sevillana». En el total de la revista 37 autores estaban relacionados o bien con la institución editora, o con la Universidad de Sevilla o el Archivo General de Indias. Como veremos más adelante el total de españoles fueron unos 88 por lo que los «sevillanos» supondrían un $40 \%$. De estos, once fueron miembros de la Escuela.

Entre 1944 y 1965 de los 31 artículos publicados sobre el Caribe, veinte tuvieron la autoría de investigadores relacionados con la Escuela de Estudios Hispano-Americanos, siendo directamente miembros de la misma seis de ellos. Esto significaría que durante este tiempo más del $65 \%$ de los trabajos de este campo en Anuario provenían de los contactos personales de la dirección de la EEHA. Durante los doce años de la dirección de Francisco Morales Padrón (1966-1977) se publicaron 28 artículos sobre el área, de los cuales seis estaban firmados por personas vinculadas con el americanismo en Sevilla y otros cuatro por miembros de la Escuela. Eso supone un $35 \%$ de trabajos vinculados con la institución, lo que significó un destacado descenso. Con Juana Gil-Bermejo (1978-1985) se publicaron en ocho años quince artículos con esta temática, de los cuales ocho fueron de investigadores vinculados a la EEHA y la Universidad de Sevilla. Estos datos señalan que con esta dirección la revista retornó a una fuerte presencia 
de producción propia o de su entorno, con un $53 \%$ de los artículos con estas características. Durante los años que el Anuario estuvo al cargo de Enriqueta Vila (1986-1992) se publicaron 42 artículos, de nueve de los cuales fueron autores investigadores vinculados a la Escuela, tres de ellos formando parte de su plantilla. Por tanto, con ella se continuó la senda de apertura de la revista al contar con tan solo un $20 \%$ de producción cercana. La dirección de Javier Ortiz de la Tabla duró apenas dos años y medio (1999-2001), publicándose ocho trabajos de los cuales dos fueron obra de personas vinculadas con la Escuela y uno más de un miembro de la misma. Durante los trece años que estuvo Consuelo Varela al frente del Anuario (2002-2014) se publicaron quince artículos sobre el Caribe, siendo siete firmados por personas vinculadas a la Escuela, de las cuales tres eran investigadores del centro, con lo que se volvió a porcentajes altos de producción de la Escuela y su entorno. Con María Luisa Laviana (2015-2018) se ha publicado un artículo cuyo autor no tiene vínculos directos con la institución.

DISTRIBUCIÓN DE TRABAJOS SOBRE EL CARIBE CON RESPECTO A LAS DIRECCIONES DEL AEA

\begin{tabular}{|c|c|c|}
\hline Directores & Años & $\begin{array}{c}\text { Artículos } \\
\text { publicados }\end{array}$ \\
\hline & $1944-1965$ & 31 \\
\hline Francisco Morales Padrón & 1966-1977 & 28 \\
\hline Juana Gil-Bermejo & $1978-1985$ & 15 \\
\hline Enriqueta Vila Vilar & 1986-1992 & 42 \\
\hline Rosario Soler Sevilla & 1993-1999 & 40 \\
\hline Javier Ortiz de la Tabla & $1999-2001$ & 8 \\
\hline Consuelo Varela & $2002-2014$ & 15 \\
\hline María Luisa Laviana Cuetos & $2015-2018$ & 1 \\
\hline TOTAL & & 180 \\
\hline
\end{tabular}

Con respecto a los investigadores españoles podemos observar una variada adscripción historiográfica. Por un lado, habría un grupo homogéneo con una metodología más tradicional, los cuales se formaron entre los años 50 y 60 del pasado siglo, como Bibiano Torres, investigador de la EEHA; 
o los profesores de la Universidad de Sevilla Fernando de Armas Medina, secretario de la revista e investigador de la Escuela, que falleció repentinamente malográndose su destacable carrera, un ejemplo del grupo de los americanistas de origen canario que se formaría en Sevilla como Morales Padrón; Luis Navarro, uno de los catedráticos que ha creado un destacado grupo, cuya herencia continua vigente hasta hoy; y Francisco Castillo, especialista en Cuba. Como discípulos de los anteriores encontraríamos a Carmen Borrego y Juan B. Amores, en una línea historiográfica más continuista, aunque con influencia de las nuevas corrientes de la historia social y económica, en la que encontraríamos también a Rosario Sevilla y Pablo Tornero, este último con una adscripción metodológica próxima al materialismo histórico, cuando no directamente a interpretaciones marxistas.

Es reseñable el caso del valenciano José Llavador Mira, que fue militante del sindicato Unión General de Trabajadores (UGT) y en 1936 fue encarcelado. En los años 50, tras salir de prisión y posiblemente gracias al apoyo de compañeros americanistas, pudo impartir clases de Historia del Derecho Indiano en la Universidad de Sevilla. ${ }^{19}$ Casos como este nos ayudan a comprender cómo las vinculaciones personales servían para superar las distancias ideológicas dando lugar a colaboraciones como la que Llavador Mira tuvo con Morales Padrón, ${ }^{20}$ algo que en la mayoría de los trabajos historiográficos consultados no suele referirse y que queda patente también en su participación en la propia revista.

Durante la dirección de Morales Padrón (1966-1977) el Anuario reforzó su carácter internacional. Desde su incorporación a la EEHA en 1954, una de sus prioridades fue tratar de estar al tanto de las novedades historiográficas, interés que se concretó en la creación de la sección de Historiografía y Bibliografía Americanistas en la revista. ${ }^{21}$ Su intención era superar el aislamiento de los distintos núcleos americanistas en España, fundamentalmente en Madrid y Sevilla. Coincidiendo con el inicio de su dirección de la revista, en 1966 convocó una serie de reuniones a nivel nacional para tomar conciencia del catálogo de investigadores americanistas españoles y debatir sobre la evolución de la materia en el marco internacional, ${ }^{22}$ teniendo muy

19 «Llavador Mira, José», http://www.fpabloiglesias.es/archivo-y-biblioteca/diccionariobiografico/biografias/11591_llavador-mira-jose [Consultado: 24/05/2018].

20 Morales y Llavador, 1963.

21 La sección de Historiografía y Bibliografía Americanistas se editaría como tirada aparte hasta que la publicación apareció como revista independiente en 1971. Funcionó como tal hasta su reintegración en el Anuario en 1987, desapareciendo en 1993.

22 Morales, 1971. 
presentes los estudios de historia del Caribe en aquel momento. No hay que olvidar que desde la década de 1960 habían empezado a transformarse los estudios de historia de América a ambos lados del Telón de Acero. Este renovado interés tenía que ver con la preocupación geopolítica mundial por el triunfo de la Revolución cubana en 1959, que implicó que América adquiriese un papel central en el mundo bipolar configurado por la Guerra Fría y que la historia debiese explicar los orígenes del fenómeno revolucionario en la Gran Antilla. Por tanto, el Caribe se situó como espacio de interés mundial y la Escuela de Estudios Hispano-Americanos, con su revista, no quedó al margen. Bajo iniciativa de Morales Padrón se celebraron congresos internacionales en Santander en 1969 y en Sevilla en 1970, ${ }^{23}$ donde se reunieron investigadores de reconocido prestigio internacional tanto occidentales como del bloque soviético. ${ }^{24}$ Una parte de estos investigadores comenzaron a colaborar con Anuario y entre sus artículos tuvieron una importancia destacada los estudios sobre el Caribe.

\section{Nacionalidades presentes}

Los autores que han publicado en Anuario de Estudios Americanos provienen de quince países distintos. Predominan de manera abrumadora los investigadores españoles con un total de 88 (aunque uno de ellos es el hispano-venezolano Pablo Ojer, y otro es Fabio López Lázaro, que, aunque nacido en España, desarrolló su carrera en Canadá). Es decir, los españoles representan el $55 \%$ de los autores. El $45 \%$ restante está repartido entre diferentes nacionalidades donde solo destacan por su número los autores franceses, que son un total de 19 , es decir un $9 \%$. Cubanos (nueve) y portorriqueños (nueve, aunque contabilizando un hispano-portorriqueño como István Szászdi) suponen un $5 \%$ en cada caso; los investigadores de República Dominicana son cinco (3\%); los estadounidenses representan el 2,5 $\%$, con cuatro autores; tres serían los investigadores de Argentina y México; mientras con dos representantes tenemos a Colombia, Venezuela, Alemania

23 Organizada por la EEHA y coordinada por el propio Morales Padrón, en ella participaron historiadores procedentes de Francia (Pierre Duviols, Jean Meyer y Jacques Lafaye), Gran Bretaña (Peter J. Bakewell, John Elliot, John Fisher y Henry Kamen), Suecia (Magnus Mörner), o la República Federal Alemana (Hermann Kellenbenz); pero también de países del otro lado del Telón de Acero, como Hungría (Tibor Witmann), Checoslovaquia (Josef Polišenky y Lubomír Vrber) y hasta de la URSS (Alexey D. Mayevsky y Alexey I. Strajov). Ventura Reja, 1970.

24 Gutiérrez, 2017. 
(uno de ellos el hispano-alemán Enrique Otte), Países Bajos y Hungría; y ya con un solo investigador Gran Bretaña y Checoslovaquia. ${ }^{25}$

Como hemos señalado, la creciente internacionalización de la revista estuvo vinculada con la dirección de la misma, especialmente tras la llegada de Morales Padrón. Valga como demostración de este hecho en el caso de los estudios sobre el Caribe el que hasta 1966 solo hubieran publicado investigadores españoles, con la excepción de los franceses Louis-André Vigneras y Gabriel Debien, ambos relacionados con el propio Morales. Hasta 1977, final de su dirección, aparecerían trabajos de Eugenio Fernández Méndez, de Puerto Rico; Ádám Szászdi, húngaro aunque afincado en la misma isla; los franceses Gabriel Debien (con dos artículos), Didier Guyvarc'h, Robert Richard y Danielle Turu; Guillermo Porras Muñoz de México; el estadounidense James A. Lewis; y el hispano-alemán Enrique Otte.

Bajo la dirección de Juana Gil-Bermejo García (1978-1985), al menos por lo que se refiere a la producción sobre el Caribe, se volvió a la tónica anterior, con la presencia casi exclusiva de españoles (en su mayoría de la escuela sevillana como Carmen Mena, Carmen Borrego, Luis Navarro, Francisco Castillo o José Luis Mora Mérida), con la única salvedad de Debien. Con Enriqueta Vila al frente de la revista (1985-1992) y apoyada en su consejo de redacción, se retomó definitivamente la línea ya marcada por Morales Padrón, algo que continuó con los demás directores. Merece la pena destacar que con Enriqueta Vila se publicaron 24 artículos sobre el Caribe, de los cuales seis eran de autores portorriqueños, cuatro de cubanos, tres de dominicanos, dos de norteamericanos y uno de un mexicano. De entre los españoles desaparece la hegemonía sevillana (aunque continúan teniendo presencia nombres como los de Pablo Tornero y Rosario Sevilla, muy alejados de líneas historiográficas tradicionales) y hay autores de dispares orígenes como Consuelo Naranjo Orovio o Candelaria Saiz Pastor, formadas en la escuela americanista madrileña; o Magdalena Guerrero Cano formada en Granada, por señalar algunos casos. Con Enriqueta Vila se publicaría el primer monográfico fundamentalmente antillano, como fue el volumen XLIII, de 1986, conmemorativo de los cien años de la abolición de la esclavitud en España.

Durante la etapa de Rosario Sevilla Soler (1993-1999), que ha dedicado su carrera a estudios sobre el Caribe, el consejo de redacción ha mantenido significativamente las líneas ya expresadas, y se fomentó la publicación

25 No he conseguido identificar la nacionalidad de Carmen Vásquez. 
de los otros dos monográficos dedicados al Caribe: en el volumen LI-2 de 1994, conmemorativo de los 50 años de la salida de Anuario de Estudios Americanos, de los trece artículos específicos seis fueron de autoría española y siete de diferentes nacionalidades como la argentina, cubana, francesa, holandesa, portorriqueña y dominicana (dos); mientras en el LV-1, de 1998, dedicado al centenario de 1898, de los catorce trabajos seis fueron firmados por historiadores de España y ocho por investigadores de Argentina, Cuba, Estados Unidos, Francia (dos), Hungría, Reino Unido y República Checa. ${ }^{26}$

Con el equipo editorial dirigido por Javier Ortiz de la Tabla (19992001) se mantendría esta tendencia con respecto al origen de los colaboradores; una línea que continúa hasta hoy sin significativas modificaciones con Consuelo Varela (2001-2014) y María Luisa Laviana (2015-2018). Bajo la dirección de Varela la revista fue incluida en 2009 en el ISI Web of Science y en el Arts \& Humanities Citation Index y en 2010 en Scopus. ${ }^{27}$ Estos son considerados los máximos reconocimiento de calidad posible.

\section{Espacios geográficos investigados}

Observando los datos queda claro que el predominio de la historia de Cuba ha sido abrumador. De los 180 artículos nada menos que 79 están dedicados específicamente a esta isla, a los que habría que sumar aquellos dedicados a las relaciones de la Gran Antilla con Puerto Rico, Santo Domingo y Luisiana (son tres más). ${ }^{28}$ En definitiva, un $45 \%$ de los artículos publicados están referidos a Cuba. Para comprender la importancia historiográfica en los estudios sobre esta isla de la publicación aquí analizada baste señalar que, cuando en 1990 Juan Bosco Amores realizó su estudio historiográfico español sobre la isla, la gran mayoría de los trabajos analizados habían sido publicados en Anuario de Estudios Americanos. ${ }^{29}$ Este interés por la isla se multiplicó aun más con la participación en los eventos conmemorativos del 98 que ya hemos señalado con anterioridad.

En cuanto al plantel de investigadores especializados en Cuba que presentaron sus conclusiones en la revista podemos considerar que constituye

26 En 1997 fue editado un CD con la digitalización de todos los artículos hasta 1996.

27 Bernabéu y Varela, 2010.

28 Estos también son contabilizados para los otros territorios por lo que los datos estadísticos podrían parecer distorsionados, pero corresponden a intersecciones en el análisis.

29 Amores, 1990. 
uno de los más completos tanto en la esfera nacional como internacional e incluso de la propia isla. Los autores cubanos son Jorge Ibarra, Carmen Barcia, Ramón de Armas, Marcos Arriaga, Francisco Pérez Guzmán, Armando García González, Fe Iglesias y Salvador E. Morales (aunque este último realizó la mayor parte de su trabajo en México). El listado de autores españoles es muy destacado. Por señalar solo a algunos citaremos a Pablo Tornero, Consuelo Naranjo, Juan Andreo García, Joan Casanovas, Antonio Santamaría, Manuel de Paz, Rosario Sevilla, Francisco Morales Padrón, Bibiano Torres, Luis Navarro García, Juan Bosco Amores o Candelaria Sainz Pastor. Entre los franceses una vez más encontramos nombres como los de Gabriel Debien, Jean-Pierre Paute, Danielle Turu, James Durnerin, Jaqueline Philip o Roland Labarre. Autores norteamericanos de primera fila prestaron sus conocimientos a la revista, como fueron Allan J. Kuethe, Rebecca Scott, James A. Lewis y Gwendolyn Midlo Hall. También profesores argentinos como Hernán Asdrúbal Silva, Eduardo L. Moyano Bazzani y Serena Fernández Alonso, se sumaron a la producción cubanista. Historiadores de otras nacionalidades que también publicaron trabajos sobre Cuba en Anuario fueron el checo Josef Opatrný, el húngaro Ádám Anderle, la británica Sylvia L. Hilton o el alemán Nikolaus Böttcher.

La segunda isla en importancia en el Caribe, La Española, tiene también el segundo lugar en el interés de los historiadores que publicaron en Anuario de Estudios Americanos. En total son 24 artículos, a los que habría que sumar uno dedicado a las relaciones con Cuba, que ya referimos antes. Por tanto, son más de un $12 \%$ de los artículos. De estos habría que especificar que trece de ellos se dedicaron de manera general a toda la isla (especialmente los que tratan los siglos XVI y XVII), cinco al Santo Domingo español y uno a Saint Domingue (al que se podría sumar otro de Debien sobre refugiados de esta parte de la isla en Cuba), ${ }^{30}$ cuatro a República Dominicana y solo uno a Haití. Los autores que han trabajado esta isla se encuentran entre los más destacados a nivel internacional. Entre los dominicanos encontramos algunos de los más significativos de las últimas décadas como Frank Moya Pons, Roberto Cassá o Emilio Cordero Michel, además de Genaro Rodríguez Morel y Raymundo González; entre los españoles por destacar algunos señalamos a Juan Gil, Antonio Gutiérrez Escudero, María Magdalena Guerrero Cano, Esteban Mira Caballos y Raúl Navarro García; también los franceses Gabriel Debien, León-François Hoffmann y Robert

30 Debien, 1978. 
Richard; el mexicano Guillermo Porras Muñoz y el hispano-portorriqueño István Szászdi. Con solo este elenco podemos hacernos una idea del nivel de los trabajos presentados y la importancia con respecto a la producción historiográfica de temática dominicana aparecida en la revista.

En consonancia a lo expuesto, el tercer espacio es la tercera isla del dominio español en tamaño, Puerto Rico. En total han sido veinte los artículos en el catálogo de trabajos, por tanto un $11 \%$. Este interés por Puerto Rico está muy relacionado con el plan trazado por Morales Padrón para colaborar en la realización de la historia moderna de dicha isla ${ }^{31}$ aprovechando el interés explícito de las autoridades académicas insulares en la internacionalización de su historiografía. En esta comunión de intereses plasmada en Anuario participaron tanto historiadores españoles ${ }^{32}$ como portorriqueños. En la revista colaboraron con esta temática profesores españoles tan destacados como el propio Morales Padrón, Bibiano Torres, Enriqueta Vila, Raúl Navarro García, Ángel López Cantos, Juana Rodríguez Macías y Cristina Campos Lacasa. En cuanto a los portorriqueños, Anuario contó con la colaboración de Fernando Picó, Andrés Ramos-Mattei, Francisco A. Scarano, Arturo Morales Carrión, Carlos D’Alzina, Francisco Moscoso, Ana María Carrillo Álvarez y Astrid Cubano. No habría que olvidar la participación de los prestigiosos profesores Paul Estrade, de Francia, y Adam Szászdi, como ya hemos dicho, afincado en Puerto Rico aunque de origen húngaro. Estos trabajos constituyeron durante años los mejores aportes historiográficos sobre la historia de Puerto Rico y hoy día siguen siendo una referencia al respecto.

Las demás islas tienen algunos trabajos, como es el caso de la isla de Trinidad bajo dominio español, con cuatro. Para el Caribe no español dominan las Antillas francesas con diez artículos, lo que supone el $5 \%$, aunque, como ya señalamos con anterioridad, cinco de ellos son informes bibliográficos; a ellos se suman un trabajo sobre los dominios holandeses y otro sobre las Islas Vírgenes. Llama la atención que Jamaica no cuente con ninguna investigación.

En cuanto al espacio no insular, el Caribe colombiano cuenta con quince investigaciones, de las cuales doce están dedicadas a Cartagena de Indias y su provincia (lo cual supondría el cuarto espacio en importancia, más del $8 \%$ del total), dos a Santa Marta y una al golfo de Urabá. De entre los autores llama la atención que de los dieciséis (uno de los artículos está

31 Calderón, 1987, CXXIV-CXXV.

32 Picó, 1999, 447. 
firmado por dos investigadores) catorce sean españoles, entre los que se encuentran Manuel Lucena Salmoral, Julián B. Ruiz Rivera, Luis Navarro, Carmen Mena, Carmen Gómez, Carmen Borrego, Juan Manuel Zapatero y José Manuel Serrano Álvarez. Los autores colombianos son Roicer Flórez Bolívar y Sergio Paolo Solano, ambos como co-autores del mismo artículo.

Por último, cabe destacar los trabajos sobre la costa venezolana, con cinco artículos, y Florida, con dos más. Hay que resaltar que se han publicado hasta dieciséis trabajos dedicados a visiones generales del Caribe, lo que supone casi un $9 \%$ del total.

\section{Épocas de estudio}

En cuanto a las épocas históricas tratadas en la revista podemos decir que hay un panorama bastante completo que abarca toda la presencia europea en el Caribe. Quizás la única carencia significativa sea la publicación de trabajos para la época prehispánica y la no muy destacada presencia de artículos para el siglo XX. Estas características son comprensibles dada la naturaleza de la propia revista, concebida en su origen como lugar para la difusión de investigaciones de estudios coloniales.

Para la Edad Moderna se han contabilizado 84 trabajos, es decir casi un $46 \%$ del total, mientras que para la Edad Contemporánea 91, lo que supone casi el $51 \%$. Se han registrado además cuatro artículos enmarcados entre los siglos XVI y XIX, que representan un $2 \%$, y otro trabajo para todo el periodo histórico entre el XVI y el XX, es decir, algo menos del uno por ciento.

Teniendo en cuenta una de las particularidades del área, como es que siguió siendo un espacio colonial español durante casi todo el siglo XIX y para el resto de potencias internacionales hasta bien entrado el siglo XX (incluso hoy día sigue siendo una de las pocas regiones del planeta con distintas variantes de dependencia de metrópolis ultramarinas), la división entre historia colonial e historia contemporánea es difusa. Por ello es de mayor interés en este caso el análisis detallado de los periodos a los que se han dedicado los diferentes artículos.

En cuanto a la Edad Moderna, el siglo XVI tiene uno de los bloques más importantes con 25 artículos (es decir, casi un $14 \%$ ). Sobre el siglo XVII se publicaron 15, lo que supone cerca de un $8 \%$. El XVIII es otro de los periodos centrales de las investigaciones publicadas en esta revista con 
26 ítems, lo que significa otro $14 \%$ del total. De especial significación son estos trabajos porque esta época no ha recibido por la historiografía toda la atención necesaria, especialmente el siglo XVIII, ${ }^{33}$ haciendo de la revista una muy importante fuente secundaria para el conocimiento de esa época.

Hay toda una serie de trabajos que abarcan unos periodos más prolongados, que comprenden varios siglos. Hay tres trabajos sobre materias que se refieren a los siglos XVI y XVII, dos para los siglos XVII y XVIII y tres que engloban desde el XVI al XVIII. Un caso específico son los trabajos centrados en los siglos XVIII y XIX, que son diez y que enlazan las dos épocas con más interés investigador, y al parecer también para la revista. Hay que señalar que destacan sobremanera los artículos dedicados al siglo XIX con un total de 76 , lo que significa nada menos que el $42 \%$ de los trabajos, lo que responde en buena medida a la atención prestada por la revista a Cuba y Puerto Rico incluso en números monográficos, como ya se ha comentado. En cuanto a otros trabajos sobre la contemporaneidad son diez dedicados al siglo XX y cuatro al XIX y al XX de manera conjunta.

Fueron de especial relevancia las aportaciones sobre época contemporánea, especialmente del siglo XIX, pues más de la mitad fueron hechas antes del año 1990 cuando la carencia en estudios sobre este periodo de la historia era una constante, ${ }^{34}$ y posteriormente la revista tomó parte en el debate que desarrolló el conocimiento de este campo.

\section{Temáticas expuestas}

Este es quizá unos de los aspectos más complicados de evaluar dada la cantidad de artículos publicados. Reconocemos por tanto que este análisis debe ser considerado como una mera aproximación orientativa.

En primer lugar, lo que se aprecia tras un análisis general es la preponderancia de los trabajos de orientación historiográfica tradicional en el americanismo español, algo comprensible por la larga vigencia de la revista. La historia política e institucional supone un total de 68 artículos, es decir, el $38 \%$ de los trabajos. De ellos, 44 están dedicados a diferentes aspectos políticos, actividades relacionadas con líneas de pensamiento, censura de prensa, consecuencias de acciones militares, presencia de extranjeros, actividades consideradas subversivas, como por ejemplo la masonería.

33 Almodóvar, 2007, 86.

34 Amores, 1990. 
En cuanto a la administración colonial han sido publicadas 24 investigaciones, que están referidas a cuestiones tan diversas como la administración política, de justicia, actividades de policía, hacienda, organización de la población, distintos aspectos del urbanismo, como por ejemplo fundaciones de ciudades. La importancia de estos trabajos es capital pues en su momento habían sido escasos los estudios monográficos sobre las instituciones y la acción de gobierno, especialmente referidos al caso de España. ${ }^{35}$ En este apartado encontramos trabajos dedicados tanto a las Antillas francesas como a los dominios españoles (Cuba, Puerto Rico, Santo Domingo, Colombia, Venezuela, Trinidad o Florida), así como los trabajos que abarcan desde el XVI al XIX, aportando una visión amplia, aunque fragmentaria. Encontramos a autores como Debien sobre las Antillas francesas en el siglo XVII y XVIII, ${ }^{36}$ István Szászdi acerca de Puerto Rico en el XVI, ${ }^{37}$ los artículos de Fernando de Armas Medina sobre temas cubanos como la organización de la Hacienda que, a pesar del tiempo pasado, constituyen obras de referencia, ${ }^{38}$ y a los que se unen las aportaciones de Joaquín Ruiz Alemán sobre la administración local ${ }^{39}$ solo por señalar algunos ejemplos.

Una temática muy cercana a la anterior y que también ha sido tradicional en los estudios de historia de América en España ha sido la referida a los aspectos militares, los cuales suman catorce y suponen cerca de un $8 \%$. En ese mismo sentido podrían entenderse los artículos dedicados al descubrimiento (dos), exploraciones geográficas (uno), cartografía (uno) y colonización (seis), otros de los asuntos clásicos del americanismo hispano. El estudio de las expediciones científicas cobró impulso en España especialmente desde la década de los 90 con los aportes de Miguel Ángel Puig-Samper, que en 1995 indicaba «la necesidad de hacer una historia de la ciencia insertada en la historia social y cultural de Cuba». ${ }^{40}$ En esa línea merece la pena destacar como un precedente tempranísimo la publicación en Anuario en 1952 del artículo de Francisco de las Barras de Aragón sobre la expedición del conde de Mopox a la isla de Cuba a finales del XVIII. ${ }^{41}$

35 Idem.

36 Debien, 1967.

37 Szászdi, 1997.

38 Armas, 1958 y 1969.

39 Ruiz, 1972.

40 Santamaría y Naranjo, 1999, 149.

41 Barras, 1952. La denominación del conde que aparece en el título del artículo (Mompox) es errónea, pues debiera ser Mopox, referido al condado de Santa Cruz de Mopox. 
Si sumamos las materias anteriores nos da una imagen muy clara del importante peso de esta interpretación clásica de la historia, pues muestra que constituyen el $64 \%$ de los trabajos publicados en Anuario de Estudios Americanos.

La renovación historiográfica iniciada en España en los primeros años de la década de 1970 también se ha visto reflejada en los trabajos aparecidos en esta publicación. Extrapolando los resultados de las investigaciones historiográficas del caso cubano, que es el mejor estudiado, en los últimos años el panorama se ha ido completando con contribuciones parciales como los trabajos que han aparecido en el Anuario con temáticas cercanas a la historia social, historia de la ciencia y de las mentalidades, así como la historia cultural. ${ }^{42}$

En Anuario la historia social está representada con 51 trabajos, aunque entre ellos tienen un peso fundamental los estudios sobre esclavitud y abolicionismo, que son en total 30 (uno de ellos dedicado a la esclavitud de los indios). Sin embargo estos datos están un tanto distorsionados porque 24 de los mismos fueron publicados en un solo volumen (el XLIII, de 1986), en el monográfico dedicado a esta temática ${ }^{43}$ La revista ha participado del debate abierto a este respecto y que ha ido profundizando aspectos tangenciales, los que son relevantes para conocer las implicaciones sociales de la esclavitud. ${ }^{44}$

En cuanto a otras temáticas puramente sociales se cuentan 27 trabajos dedicados a cuestiones poblacionales (ocho), la emigración, el movimiento obrero, la cultura popular, el papel de la mujer, la sanidad, la prostitución, la situación de los indios en los primeros años de dominio europeo, o incluso la piratería desde un aspecto biográfico. Nos gustaría llamar la atención sobre cómo uno de los aspectos que caracteriza de manera general el Caribe, como es la piratería, tiene una mínima presencia, casi testimonial. Esta no es una carencia excepcional de la revista a estudio, sino que es extensible a toda la historiografía en español, ${ }^{45}$ mientras la historiografía anglosajona tiene un consolidado bagaje al respecto.

Sin embargo, en aspectos de la vida rural, señalada como mal conocida por algunos autores ${ }^{46}$ el Anuario ha publicado un par de artículos muy

42 Santamaría y Naranjo, 1999.

43 Amores, 1990.

44 Santamaría y Naranjo, 1999.

45 Se debe señalar que Morales Padrón ha sido de los pocos que se han preocupado por esta temática.

46 Santamaría y Naranjo, 1999 
interesantes, que se refieren a espacios alejados de las áreas centrales, como es el trabajo de Gwendolyn M. Hall sobre la manumisión de esclavos en Luisiana ${ }^{47}$ o el de Genaro Rodríguez Morel sobre la vida rural del esclavo en las plantaciones azucareras de La Española en el siglo XVI, una época poco estudiada. ${ }^{48}$

Llama la atención que una de las líneas historiográficas fundamentales para el Caribe como ha sido la emigración, tiene una presencia limitada. Desde el principio de la década de los 80 aumentó el interés por explicar los flujos migratorios entre Europa y América. El Caribe, y en especial Cuba, ha sido escenario de estas migraciones fundamentalmente en el siglo XIX y principios del $\mathrm{XX}^{49}$ En la revista tres autores han tratado esta materia, como son Francisco Castillo Meléndez, Pablo Tornero y Rosario Márquez Macías. ${ }^{50}$ A estos se podría unir el trabajo de Joan Casanovas, ${ }^{51}$ que se refiere al movimiento obrero en Cuba, una cuestión derivada de la emigración española en la isla. Esta temática también ha encontrado eco entre investigadores de la última década del siglo XX y las primeras del XXI con unas aportaciones muy importantes. ${ }^{52}$ Relacionado con lo anterior, nos encontramos con los estudios que han venido desarrollándose sobre la cultura derivada de esta emigración..$^{53}$ En este caso podemos señalar el trabajo de José Antonio Vidal Rodríguez sobre las tradiciones culturales gallegas en Cuba. ${ }^{54}$

Otras de las líneas historiográficas que han tenido una presencia más destacada desde los 70 del siglo XX ha sido la historia económica, que tiene en la revista una significativa representación. De manera general la historia económica de la isla de Cuba ha sido un campo de estudio que se ha ido enriqueciendo en los últimos decenios, especialmente en lo concerniente a los siglos XVIII y XIX, convirtiéndose en preferente para los investigadores. ${ }^{55}$ Como parece lógico, en numerosas ocasiones esta temática está relacionada con los asuntos referentes al azúcar o la esclavitud. Por eso merece la pena destacar que uno de los máximos especialistas en su momento, Pablo

47 Hall, 1986.

48 Rodríguez, 1992.

49 Almodóvar, 2007, 18.

50 Castillo, 1983. Tornero, 1987. Márquez, 1991.

51 Casanovas, 1998.

52 Almodóvar, 2007, 34-35.

53 Ibidem, 37.

54 Vidal, 2002.

55 Almodóvar, 2007, 13. 
Tornero, publicó en la revista dos de sus más destacados trabajos que siguen una metodología marxista. ${ }^{56}$ Tornero puso de manifiesto la relación entre los tres factores determinantes de la economía caribeña: «la acumulación de tierra y capital en manos de los hacendados y comerciantes, la introducción masiva de mano de obra esclava y la lucha por el libre comercio». ${ }^{57}$ Por tanto, la revista se ha hecho eco de esta corriente, lo que la convierte en una referencia para estos asuntos de interrelación entre azúcar y esclavitud. En total son trece artículos los que se han dedicado a la economía, en los que hay un peso determinante de las actividades económicas relacionadas con la explotación de la caña, pues la mitad de los mismos están dedicados a diferentes aspectos de esta materia. También hay testimonios de algunos artículos centrados en el comercio, algún otro sobre el tabaco, como el de Antonio Gutiérrez, ${ }^{58}$ y hasta la minería, como el de los argentinos Eduardo Moyano y Serena Fernández. ${ }^{59}$ Muchos de estos trabajos entrelazan aspectos sociales y económicos.

Otro bloque historiográfico que consideramos debe ser señalado de manera específica es el dedicado a la historia cultural, con unos diecinueve trabajos. Es cierto que se trata de una corriente bastante en boga en las últimas décadas, pero en algunos aspectos ya venía siendo tratada como ocurría con la historia de la Iglesia (que igualmente podría ser considerada dentro de los trabajos sobre administración colonial desde una perspectiva clásica). Encontramos algunos trabajos que van desde el pensamiento político hasta la música. El papel de la prensa y la opinión pública y la influencia de las publicaciones periódicas ha sido otro de los temas que ha centrado el interés de numerosos investigadores. ${ }^{60}$ Aquí tenemos interesantes ejemplos en los artículos de Rosario Sevilla ${ }^{61}$ y Carmen Borrego, ${ }^{62}$ sobre diferentes aspectos de la prensa andaluza y el fin del dominio colonial español en el Caribe; Josef Opatrný con la misma temática, pero en este caso referido al caso de la prensa checa; ${ }^{63}$ o María del Carmen Barcia,${ }^{64}$ con una investigación sobre una editora cubana de finales del XIX y principios del XX. Este trabajo

56 Tornero, 1986. El otro artículo ha sido reseñado más arriba.

57 Amores, 1990. Almodóvar, 2007, 68-71, reseña esta característica.

58 Gutiérrez, 2001.

59 Moyano y Fernández, 1998.

60 Almodóvar, 2007, 50-51.

61 Sevilla, 1986 y 1994.

62 Borrego, 1998.

63 Opatrný, 1998.

64 Barcia, 2001. 
podría considerarse además como un ejemplo de otra de las tendencias historiográficas con una presencia creciente como es la historia de género.

El último bloque de publicaciones han sido las referidas a bibliografía (seis) e historiografía (cinco), que en total suman once trabajos. En este caso la escasez de estos trabajos se justifica en la existencia de la sección de Historiografía y Bibliografía Americanistas, creada por Francisco Morales Padrón en 1954 y que durante un tiempo se editó como tirada aparte hasta que la publicación apareció incluso como revista independiente entre 1971 y 1987, cuando volvería a reintegrarse en el Anuario. ${ }^{65}$

Hemos detectado que los artículos representativos de corrientes historiográficas en boga en las últimas décadas, postmodernas, new cultural o postcolonial studies, son poco frecuentes en el Anuario, al menos en lo que respecta a lo editado sobre el Caribe, ni siquiera en lo que se refiere a la perspectiva de género - si exceptuamos el caso señalado de Carmen Barcia-, el retorno de lo político, el análisis lingüístico y deconstructivo de los discursos, la microhistoria o la historia atlántica. Como antecedentes recientes, en la década de 1990 autores que difícilmente aceptarían en su mayoría ser catalogados con tales etiquetas sí plantearon tesis vinculadas con sus planteamientos, la dominación y fragmentación colonial, un enfoque revisionista de la independencia dominicana, como fueron los casos de Moya Pons y Roberto Cassá, ${ }^{66}$ así como el análisis de la formación de identidades o de los debates por entonces de interpretación del pasado de las Antillas, como los de Anne Pérotin-Dumon. ${ }^{67}$ Esto no significa que el Anuario haya quedado completamente al margen de estas líneas actuales, aunque los únicos casos directamente relacionados con esta corriente han quedado fuera de este estudio por tratarse de trabajos sobre literatura. ${ }^{68}$

Más comunes, como en los antecedentes referidos, son los usos de nuevos métodos, perspectivas y fuentes, en la exploración de temáticas poco tratadas u omitidas por la historiografía tradicional. Unos pocos trabajos han sido editados en la revista en los últimos años, aunque solo sea por la importancia y cantidad de autores, vinculados con la renovación reciente de los estudios con una mirada interdisciplinar y multicultural. Esto

65 Gutiérrez, 2017.

66 Moya, 1994. Cassá, 1994.

67 Pérotin-Dumon, 1994 y 1995.

68 El único artículo publicado en el Anuario sobre el Caribe con enfoque per se postmoderno, culturalista y postcolonial es el de Julio Ortega (2004) sobre el uso del lenguaje vinculado a la dominación occidental y la resistencia frente a ella, aunque podría añadirse el estudio de Emilio Gallardo (2007) acerca del teatro postmoderno del cubano Virgilio Piñera. 
es especialmente evidente en los análisis de la esclavitud y su legado, de la inmigración o el medio-ambiente, y como ejemplos pueden mencionarse el de Martín Rodrigo acerca de la deuda ecológica de la expansión de la industria azucarera en la Gran Antilla ${ }^{69}$ o el de Julio A. Yanes respecto a las evidencias micro-macroespaciales que desmienten la llamada migración «golondrina» de canarios a Cuba en el inicio del siglo XX. ${ }^{70}$

\section{A modo de conclusión}

Teniendo en cuenta todos los datos expuestos podría concluirse que Anuario de Estudios Americanos es una publicación de referencia para estudiar el ámbito caribeño en general, aunque especialmente para aquellos historiadores que se dediquen a investigar el Caribe hispano, principalmente en lo que respecta a la isla de Cuba, durante el siglo XIX y en las temáticas de historia política y sobre la esclavitud. Además debe ser una fuente secundaria de referencia para los demás espacios caribeños y épocas, pues en ella han publicado los más destacados especialistas tanto españoles y europeos como americanos, y sobre las temáticas más variadas y consideradas fundamentales en este campo de estudio. En este breve y circunstancial estudio historiográfico se han esbozado las líneas fundamentales que han caracterizado a los estudios sobre el Caribe en Anuario de Estudios Americanos. Hemos tratado de destacar las principales características, sus mayores aportaciones y hemos señalado alguna de sus carencias, propias en cualquier caso de una publicación periódica. La sucesión en gran parte inconexa, salvo las señaladas y meritorias excepciones de los monográficos, demuestran sobre todo una participación en los principales temas de debate según las épocas por las que ha navegado la revista desde 1944 hasta ahora. Los numerosísimos aportes a la historia del Caribe en sus diversas temáticas, de todas las épocas históricas y en la mayor parte de los múltiples espacios geográficos de la región a estudio, contribuyen con su especificidad a completar el conocimiento sobre este espacio cardinal para comprender la Historia no solo de América sino mundial.

69 Rodrigo, 2006.

70 Yanes, 1998. 


\section{Referencias bibliográficas}

Almodóvar Muñoz, Carmen, Presencia de Cuba en la historiografía española actual, Madrid, Ediciones Doce Calles, 2007.

Amores Carredano, Juan Bosco, «Historiografía española sobre Cuba colonial (1940-1989)», Revista de Indias, L, 188, Madrid, 1990, 243-255.

Armas Medina, Fernando de, «La Audiencia de Puerto Príncipe (1775-1853)», AEA, XV, 1958, 273-370.

Armas Medina, Fernando de, «Organización de la Real Hacienda en la isla de Cuba hasta la creación de la Intendencia», AEA, XXVI, 1969, 1-64.

Barcia Zequeira, María del Carmen, «Eva Canel, una mujer de paradojas», AEA, LVIII-1, 2001, 227-252.

Barras de Aragón, Francisco de las, «Noticias y documentos de la expedición del conde de Mompox a la isla de Cuba», AEA, IX, 1952, 513-548.

Bernabéu, Salvador y Varela, Consuelo, «La Escuela de Estudios Hispano-Americanos y sus revistas: de la imprenta a Internet», Nuevo Mundo Mundos Nuevos, Nuevo Mundo Anniversaire 2010 - Une décennie américaniste en ligne 2010, https://journals.openedition.org/nuevomundo/59903. [Consultado: 24/05/2018].

Borrego Plá, María del Carmen, «El Puerto de Santa María ante 1898», AEA, LV-1, 1998, 189-208.

Bouche, Denise, «Nécrologie. Gabriel Debien (1906-1990)», Revue française d'histoire d'outre-mer, 77, 287, 1990, 213-215, https://www.persee.fr/doc/ outre_0300-9513_1990_num_77_287_2787. [Consultado: 24/05/2016].

Calderón Quijano, José Antonio, El americanismo en Sevilla, 1900-1980, Sevilla, EEHA-CSIC, 1987.

Casanovas Codina, Joan, «El movimiento obrero cubano durante la Guerra de los Diez Años (1868-1878)», AEA, LV-1, 1998, 243-266.

Cassá, Roberto, «Revisionismo historiográfico acerca de la independencia dominicana», AEA, LI-2, 1994, 273-300.

Castillo Meléndez, Francisco, «La emigración de familias canarias a la isla de Cuba en el último cuarto del siglo XVII», AEA, XL, 1983, 411-467.

Consejo de Redacción, «El Caribe: de colonia a república», AEA, LI-2, 1994, 13.

Debien, Gabriel, «Les affranchissements aux Antilles Françaises aux XVIIe et XVIIIe siecles», AEA, LIV, 1967, 1177-1203.

Debien, Gabriel, Les esclaves aux Antilles françaises (XVII ${ }^{e}$-XVIII ${ }^{e}$ siècles), BasseTerre, Société d'Histoire de la Guadeloupe / Fort-de-France, Société d'Histoire de la Martinique, 1974.

Debien, Gabriel, «Réfugiés de Saint-Domingue expulsés de La Havane en 1809», AEA, XXXV, 1978, 555-610.

Espino López, Antonio, «Sobre la creación de fronteras. El caso de La Española y las guerras del reinado de Carlos II, 1673-1697», AEA, 75-1, 2018, 157-184. 
Gallardo, Emilio, «Atarse a estacas como trepar a mástiles: el trac piñeriano», AEA, 64-2, 2007, 253-266.

Grafenstein, Johanna von, Nueva España en el Circuncaribe, 1799-1808. Revolución, competencia imperial y vínculos intercontinentales, México, UNAM, 1997.

Gutiérrez Escudero, Antonio, «Tabaco y desarrollo económico en Santo Domingo (siglo XVIII)», AEA, LVIII-2, 2001, 713-736.

Gutiérrez Escudero, Antonio, «Francisco Morales Padrón y la internacionalización del americanismo hispano. Notas para una biografía», XXII Coloquio de Historia Canario-Americana (2016), Las Palmas de Gran Canaria, 2017, XXII-150, 1-8.

Hall, Gwendolyn Midlo, «Raza y libertad: la manumisión de los esclavos rurales de La Luisiana bajo la jurisdicción del capitán general de Cuba», AEA, XLIII, 1986, 365-376.

Higman, B. W. (ed.), General History of the Caribbean. Vol. VI. Methodology and Historiography of the Caribbean, London, UNESCO Publishing, 1999, 388-418.

Márquez Macías, Rosario, «La búsqueda de un modelo laboral capitalista en la economía cubana. La emigración de colonos canarios, 1852-1855», AEA, XLVIII, 1991, 557-584.

Morales Padrón, Francisco, «Introducción», AEA, XXVIII, 1971, XV-XVII.

Morales Padrón, Francisco y Llavador Mira, José, «Mapas, planos y dibujos sobre Venezuela existentes en el Archivo General de Indias», AEA, XX, 1963 , 533-618.

Moya Pons, Frank, «Introducción al Caribe: dominación y fragmentación colonial», AEA, LI-2, 1994,17-24.

Moyano Bazzani, Eduardo y Fernández Alonso, Serena, «La minería cubana en las últimas décadas del siglo XIX», AEA, LV-1, 1998, 221-242.

Naranjo Orovio, Consuelo y García, Alejandro (coords.), «Cuba 1998», Revista de Indias, LVIII, 212, Madrid, 1998.

Opatrný, Josef, «La guerra hispano-norteamericana en la prensa checa de fines del siglo XIX», AEA, LV-1, 1998, 103-124.

Ortega, Julio, «La isla de Calibán», AEA, 61-1, 2004, 141-145.

Pérotin-Dumon, Anne, «Histoire et identité des Antilles françaises: les prémisses d'une historiographie moderne», AEA, LI-2, 1994, 301-315.

Pérotin-Dumon, Anne, «Les ancêtres d'Aimé Césaire et d'Alexis Leger: l'historiographie des Antilles Françaises, 1970-1990», AEA, LII-2, 1995, 299-316.

Rodrigo, Martín, «Los amargos beneficios del dulce. Azúcar, Cuba y deuda ecológica», AEA, 63-1, 2006, 211-232.

Rodríguez Morel, Genaro, «Esclavitud y vida rural en las plantaciones azucareras de Santo Domingo. Siglo XVI», AEA, XL, 1992, 89-117.

Ruiz Alemán, Joaquín, «Los municipios cubanos en el bienio constitucional», AEA, XXIX, 1972, 379-387. 
Santamaría García, Antonio, «La revolución cubana y la economía, 1959-2012. Los ciclos de política y el ciclo azucarero», AEA, 71-2, 2014, 691-723.

Santamaría García, Antonio y Naranjo Orovio, Consuelo, «La historia social de Cuba, 1868-1914. Aportaciones recientes y perspectivas», Historia social, 33, Valencia, 1999, 133-158.

Sevilla Soler, Rosario, «La intervención norteamericana en Cuba y la opinión pública andaluza», AEA, XLIII, 1986, 469-516.

Sevilla Soler, Rosario, «Reacciones a la independencia de Cuba: el caso de la prensa sevillana», AEA, LI-2, 1994, 175-187.

Szászdi, István, «Gobierno e inicio de la recaudación áurea en el Nuevo Mundo», AEA, LIV-2, 1997, 617-638.

Tornero Tinajero, Pablo, «Ingenios, plantación y esclavitud: una aproximación al estudio de los esclavos en los ingenios cubanos (1760-1821)», AEA, XLIII, 1986, 35-68.

Tornero Tinajero, Pablo, «Emigración, población y esclavitud en Cuba (17651817)», AEA, XLIV, 1987, 229-280.

Vázquez Cienfuegos, Sigfrido y Amores Carredano, Juan B., «En legítima representación: los firmantes del fallido proyecto de Junta de La Habana en 1808», AEA, 68-1, 2011, 105-139.

Ventura Reja, José, «La Segunda Reunión de Americanistas Europeos (Sevilla, 13-20 de septiembre de 1970)», Revista de Historia de América, 70, Madrid, 1970, 488-492.

Vidal Rodríguez, José Antonio, «La reconstrucción de la identidad gallega en Cuba: procesiones, festivales y romerías regionales en La Habana (18041920)», AEA, LIX-2, 2002, 511-540.

Yanes, Julio A., «Evidencias micro y macroespaciales canarias que desmienten la emigración golondrina a Cuba durante el primer tercio del siglo $\mathrm{XX}$ », AEA, LV-2, 1998, 603-625. 